upper layers of the ocean. The ice sheet survives due to colder conditions maintaining a protective screen of ice crystals (diamond dust) in the atmosphere. A further necessary condition is the presence of a large continent at a high latitude.

The author draws on many scientific papers and books to make his case. His sections on plate tectonics, on the Earth as a heat engine and on the probability of asteroid impacts give useful summaries, as do the technical notes on radiocarbon dating, on the Earth's magnetic polarity and on oxygen isotope analysis.

However to make the case of his "instant"' ice age, the author has to reject too many well-established concepts to convince a scientific mind of the validity of his model. He refers to a "mistaken belief that ice ages were caused by an enormous expansion of mountain glaciers"'. He states that "Ice can, of course, flow any distance, as long as it does so on a downward slope, but across the North Sea we are not concerned with a downward slope'. Because he considers ice cannot flow over flat surfaces, he rejects the idea that Scandinavian erratics could have been carried to England by ice sheet motion and returns to the ice rafting concepts of last century. On inland regions, he suggests that erratics skate over smooth ice sheets, even being blown uphill. It is not quite clear if he is serious, as his introduction refers to this by saying, "If my attempt to find such a different process does not commend itself, I am happy to leave it to the reader to find a better one!'”. His proposal to prevent the next ice age by pumping up deep ocean water for a millenium or more must be seen as science fiction at this time.

The search for evidence of meteorite impacts and their effect on the Earth is a challenging problem that was recently discussed by Kyte et al. (Nature 292, 417). They found traces of meteoric debris of 2.3 million years of age in a deep core from the Antarctic Ocean, but this was not associated with any biological extinctions or environmental changes. However with a minimum diameter estimated at $20 \mathrm{~m}$, it may not have been large enough to test the ice age hypothesis. The increasing evidence in favour of solar orbital hypotheses as a cause of ice ages is ruled out by Hoyle because the total input of heat to the Earth varies little, and he considers latitudinal variation of heat input insufficient to cause ice sheet growth.

It seems surprising that Sir Fred Hoyle, who has developed the idea of continuous creation in the Universe, should go for a "big bang" theory of climate at this time. This is a pity as, with some restraint, more consideration of recent evidence such as that from ice cores and some limited changes of argument, the book could have provided an excellent layman's guide to problems of climatic change and ice ages.

\title{
A voyage to the ancient oceans
}

\section{James P. Kennett}

Paleoceanography. By T.J.M. Schopf. Pp.341. ISBN 0-674-65215-0. (Harvard University Press: 1980.) \$32.50, £17.50.

UNTIL now, no book has attempted to bring together the various aspects of the burgeoning field of palaeoceanography, the newest of earth science disciplines and one almost undreamed of only two decades ago. Thomas Schopf's Paleoceanography thus provides an important compilation of material about the ancient oceans. $\mathrm{His}$ is a holistic view - the recognition of the close interactions between the major components of the Earth's environment. The breadth of inquiry is large, as required for any synthesis of data and theories on the ancient ocean's environmental conditions; for instance, the reader will move from discussions about oxygen and carbon isotopes, to taxonomic diversity, to boron as a palaeosalinity indicator.

Schopf asks important questions about the evolution of the global ocean related to its origin, its volume, its chemistry and its life. For each of seven major parameters analysed, such as temperature and biology, he includes summaries of modern conditions, methods of study and history of change. We learn, for instance, that global biological productivity has not varied by more than a factor of two during the last 3.3 billion years, even though taxonomic groups have undergone considerable change.

An overview is attempted of the evolution of the oceans during the entire history of the Earth, but the size of this topic has naturally limited the scope of the book. Conspicuously absent, for the most part, are the recent findings on the deep ocean basins and pelagic realm which have resulted from the study of deep-sea sediments. The deep-sea drilling project is barely mentioned. Instead Schopf has concentrated his efforts upon the shallowwater marine sedimentary record and inevitably upon the pre-Mesozoic ocean. $\mathrm{He}$ is at his best when describing the Precambrian ocean. Those more interested in the late Phanerozoic record will need to look hard for information; nevertheless, Schopf usually attempts to work from first principles, and thus the student interested in any period will be enlightened.

Although each of the chapters is well organized, the overall focus of the volume is somewhat elusive. This partly results from the lack of a final synopsis which could have usefully been included to integrate the numerous concluding statements from each of the chapters. A coherent evolutionary picture of the oceans does not emerge easily from this volume.

Despite its limitations, this is a most informative and stimulating book which should be read by all students of the ocean; after all the oceans are the product of their history. The majority of palaeoceanographers - those working in the Cenozoic and late Mesozoic - will find the ocean as viewed by Schopf to be largely unfamiliar, but it should strengthen their understanding of more recent oceanographic evolution. The book has broad appeal and I would also recommend it as a text in senior-level courses dealing with palaeoceanography and marine palaeoenvironments, not so much for its comprehensiveness, but because it will promote awareness of the more unfamiliar ancient ocean.

James P. Kennett is a Professor of Oceano graphy at the University of Rhode Island, Kingston.

\section{Malaria: still cause for concern}

\section{R.J.M. Wilson}

Malaria. Edited by Julius P. Kreier. Vol.1 Epidemiology, Chemotherapy, Morphology, and Metabolism, pp.416, ISBN 0-12-426106-9; Vol.2 Pathology, Vector Studies and Culture, pp.328, ISBN 0-12-426102-7; Vol.3 Immunology and Immunization, pp.345, ISBN 0-12-426103-5. (Academic: 1980.) Vol.1. \$49, £32.40; Vol.2. \$38.50, £25.50; Vol.3. \$39.50, $£ 26.20$.

MALARIA remains the most important parasitic disease of human beings in terms of mortality and morbidity. In the early $1950 \mathrm{~s}$, malaria eradication was attempted in many countries and as a result the disease receded from the temperate zone where its epidemiology was unstable. There has been, however, a major resurgence of endemic malaria in Central America and Southern Asia due to the emergence of vector mosquitoes resistant to insecticides and parasites resistant to chemotherapeutic drugs, and to a reduction of malaria control measures as financial resources have been withdrawn. Today, the malarious regions of the world still encompass some 1,600 million people. Even in peripheral areas such as the UK, cases of malaria arising from business and tourist travel increased from 134 in 1970 to 2,503 in 1979 . Clearly, the slackening of malaria control measures has had serious consequences, and in this context it is ironic to note that the UK government has recently withdrawn its support to the WHO's well-publicized Six Diseases Programme with its strong emphasis on malaria.

In this volatile situation, a new broadly- 